\section{CHOLINE AND THE INTESTINAL ABSORPTJON OF FAT}

$\mathrm{F}^{\mathrm{n}}$ RAZER ${ }^{1}$ has reported the presence of large globules of stainable fat in the epithelium of the intestinal vilh of rats killed three hours after they had received olive oil and water by mouth; but in the cores of the intestinal villi he could demonstrate very Hittle fat. However, three hours after the oral administration of comparable amounts of olive oil with added choline, masses of fat were now found in the cores of the villi, whereas the epithelial cells had been more rapidly cleared. The fat which remained in the epithelium was more finely dispersed. We have re-investigated this problem using various procedures, including that described by Frazer. In a small number of animals the pictures which he has described were seen, but our findings in general have not supported his conclusions.

Experimental. Forty-four young adult rats (100$150 \mathrm{gm}$.) of the Wistar strain were used, six of which were males, the remainder females. With twenty, Frazer's experimental technique was carefully followed. To normal animals, starved 24 hours, either distilled water (1 c.c.) or 0.5 per cent aqueous choline chloride ( 1 c.c.) was administered by stomach tube, followed by an equal volume of olive oil. The test meal was not emulsified before feeding, for Frazer ${ }^{2}$ has shown that three to four hours after 1 c.c. of olive oil has reached the stomach of a rat, it can be recovered as finely and stably emulsified $(0.5 \mu)$ particles from the chyme.

After three hours, the rats were anæsthetized with sodium amytal and killed by the production of double pneumothorax. The gastro-intestinal tract was removed immediately, slit longitudinally, and fixed for at least 48 hours in 10 per cent formal saline, Four fasted rats, receiving no test meal, were used as controls.

Twenty rats were employed in studies in which variations from the routine procedure described above were introduced. These included altering the dose of choline chloride, emulsifying the test meal, vitally staining the olive oil, feeding choline-deficient and synthetic normal diets before the experiment, allowing $\frac{1}{2}-6$ hours for the fat absorption, and using different anæsthetics. None of these modifications affected the results obtained.

Longitudinal, frozen $(5-\mu)$ sections of jejunum were stained for 10 minutes with Sudan IV according to Lillie's technique ${ }^{3}$. One of us (R. R. T.) modified this procedure by substituting I per cent Fast Green FCF in 1 per cent aqueous acetic acid (5-30 sec.) for the conventional hæmatoxylin counterstain. This technique was more precise than the classical Sudan IV and hæmatoxylin method ${ }^{4}$, which tended to mask small lipid droplets. Sections of other regions of the gastro-intestinal tract were also prepared. The entire small intestine from six of the rats was rolled and imbedded in gelatin so that the total length between pylorus and cæcum was represented on each section. From the tissue of rats fed vitally stained olive oil, $300-\mu$ sections, unstained for fat, were cut to demonstrate the distribution of the absorbed lipid. From the 44 rats, a total of 211 sections was studied.

Results. The accompanying table [p. 156] summarizes the observations made on the 211 intestinal sections which contained appreciable fat. These have been analysed to compare our findings with those that would be predicted from Frazer's report.

In Group I, only eleven of the 69 sections, and in Group II, only two of the 20, support Frazer's observations. It will be noted that even in the intestines of rats fed only fat and water, no constant control picture has been obtained. In general, a fat-filled epithelium was accompanied by an equally well-filled villus core, and the converse was also true. This occurred regardless of the presence or absence of choline in the test meal. When the epithelium was heavily laden with fat, the latter was present in larger globules than when smaller amounts were found.

This again was not affected by the presence of choline in the test meal. We have often observed, moreover, both pictures described by Frazer (Figs. 1 and 2) in different regions of the intestine of the same rat. No difference whatever could be seen

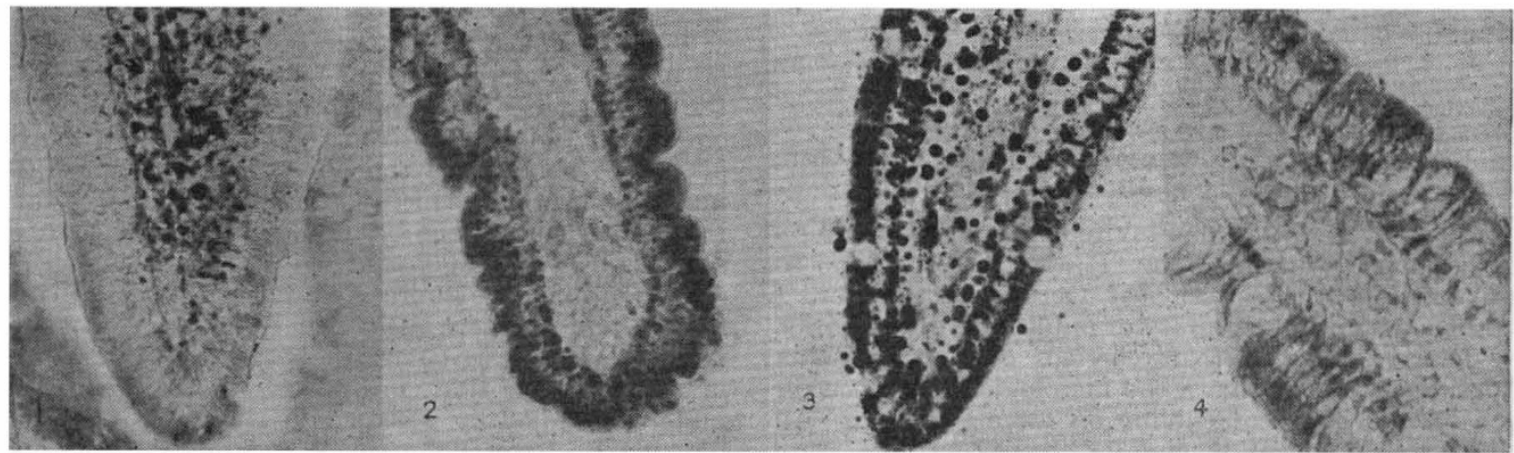

Frozen $(5-\mu)$ sections of villi from the upper intestine, stained with Sudan IV (isopropyl technique of Lillie) and Fast Green FCF, $\times 320$, photographed with Wratten $G$ and $H$ filters.

Fig. 1. Abundant fat in the core of the villus, but little in its epithelium. This has been described by Frazer as typical of the intestinal villi of rats three hours after meals of 1 c.c. olive oil plus 1 c.c. of 0.5 per cent choline chloride. (The rat from which the villus illustrated was taken, however, had been given oil and water.

Fig. 2. Epithelium packed with fat, and the empty villus core described by Frazer as typical of villi taken from rats 3 hours after meals of 1 c.c. olive oil plus 1 c.c. water. (The rat from which this was taken, however, had been given oil and choline.)

Fig. 3. Since different villi from the same rat showed various pictures, it was necessary to analyse the sections according to whether the average picture resembled more closely Fig. 1 or Fig. 2 . In many cases the picture was mixed: large amounts of fat in both the epithelium and the core were seen, as in this section. (The rat from which this was taken received oil and choline.) Sections resembling Fig. 3 are described as exhibiting a picture intermediary between Figs. 1 and 2.

Fig. 4. A villus taken from a rat starved 24 hours, which received no test meal. The epithelium contained dust-like, Sudan-pcsitive material, and the core of the villus was devoid of stainable lipid 


\begin{tabular}{|c|c|c|c|c|}
\hline $\begin{array}{l}\text { Fxperi- } \\
\text { mental } \\
\text { group }\end{array}$ & $\begin{array}{l}\text { Supplement } \\
\text { fed with } \\
\text { olive oil }\end{array}$ & \multicolumn{2}{|c|}{$\begin{array}{l}\text { No. of sections showing } \\
\text { a picture described by } \\
\text { Frazer as typical of } \\
\text { rats fed: }\end{array}$} & $\begin{array}{c}\text { No. of } \\
\text { sections } \\
\text { showing an } \\
\text { intermediary } \\
\text { picture } \\
\text { (see Fig. 3) }\end{array}$ \\
\hline \multirow{2}{*}{$\underset{\text { studied }}{\text { All }}$} & $\begin{array}{l}\text { Choline } \\
\text { chloride }\end{array}$ & 2 & 8 & 27 \\
\hline & Water & 8 & 9 & 15 \\
\hline \multirow{2}{*}{$\begin{array}{c}\mathrm{II} \\
20 \mathrm{rats} \\
\text { treated } \\
\text { precisely } \\
\text { as H razer } \\
\text { prescribed }\end{array}$} & $\begin{array}{l}\text { Choline } \\
\text { chloride }\end{array}$ & 0 & 4 & 6 \\
\hline & Water & 4 & 2 & 4 \\
\hline
\end{tabular}

between the fat in the intestines of the normal rats fed oil and choline and those given oil and water.

Finally, Cramer and Ludford $^{3}$ found that the amount of stainable fat present in the epithelial cells was increased by the administration of "vitamin B" ('Marmite'), and that this was accompanied by an increase in the size and complexity of the Golgi network. We studied this organelle after impregnation with osmic acid ${ }^{6}$. Although the extent of the Golgi structure varied directly with the amount of fat observed in the epithelial cells, neither was affected by the administration of yeast, cod liver oil concentrate or choline chloride.

Summary and Conclusion. The experiments described above were designed to investigate the histological evidence for the alleged effect of choline on fat absorption. All known variables influencing fat absorption, including those outlined by Frazer, were carefully controlled. The results provide no support for the claim that choline affects the distribution or dispersion of fat in the intestinal villi during fat absorption.

We wish to thank Prof. C. H. Best for his helpful advice.

\section{R. R. TASKER}

W. Stanley Hartroft

\section{Banting and Best Department}

of Medical Research,

University of Toronto.

${ }^{1}$ Frazer, A. C., Nature, 157, 414 (1946).

Frazer, A. C., J. Physiol., 103, 306 (1944).

${ }^{3}$ Lillie, R. D., "Histopathologic Technic", 159 (Blakiston Co., Thiladelphia and Toronto, 1948).

4Herxheimer, G., Centralbl. algem. Path. u. path. Anat., 14, 891 (1903).

${ }^{5}$ Cramer, W., and Ludford, R. J., J. Physiol., 60, 342 (1925).

'Ludford, R. J., J. Roy. Mic. Soc., 107 (1926).

Prof. C. H. Best has invited me to comment on the above communication. I have already done so privately to Prof. Best last October; however, I appreciate this opportunity of publishing my remarks.

Tasker and Hartroft carried out experiments "designed to investigate the histological evidence for the alleged effect of choline on fat absorption. All known variables influencing fat absorption . . . were carefully controlled." Their experiments consist of histological studies on 44 rats. In a group of 20 animals they attempt to repeat some experiments of mine ${ }^{1}$. They claim to have studied and accurately assessed more than twelve variables in a further group of 24 rats.

The problem of the effect of choline on fat absorption is a living dynamic problem. Fat is absorbed through the intestinal cells and passes from them through the corium of the villus to the lacteal. Quite clearly the presence of fat in the corium of the villus depends upon the relationship of the rate of transference of fat from the cells into the corium and the rate of removal from the corium into the lacteals. The amount observed is obviously not only dependent on the relative rates, but also upon the actual quantities of fat being transported, and, possibly, on the state of dispersion of the fat. These various factors are in turn dependent upon the amount of fat fed, the gastric emptying-rate, intestinal motility, and the presence of phosphate and other substances. It is possible in a long series of carefully planned experiments to obtain reasonably consistent results histo. logically. Even so, morphological studies alone do not justify any firm conclusion, because fundamental quantitative information is lacking.

In order to assess the histological picture of fat absorption, or to compare or contrast it with any other observation, it is essential that certain important variables should be controlled and some of them quantitatively assessed. The most important points are stomach emptying-time, the quantity of fat absorbed, the presence of choline or choline-contain. ing substances from other sources, and the presence or absence of phosphates. Tasker and Hartroft have neither controlled nor investigated any of these vitally important factors in their experiments.

They state that their Fig. I would be described by me "as typical of the intestinal villi of rats three hours after meals of 1 c.c. olive oil plus 1 c.c. of 0.5 per cent choline chloride". It certainly would not. The relatively small amount of fat in the corium of the villus and the completely cleared intestinal cells $3 \mathrm{hr}$. after the administration of 1 c.c. of olive oil is, in my experience, more probably due to inter. ference with gastric and intestinal motility than to choline. Such an appearance may be seen in moniodoacetic acid intoxication, which causes gross interference with gastric and intestinal motility. Fig. 2 shows moderate loading of the intestinal cells. Fig. 3 is rather more like the choline effect than Fig. 1, if faulty fixation can be excluded. None of the photographs reproduced in their paper shows a characteristic choline effect as described by me. Using these histological criteria, it is scarcely surprising that the results of their investigations do not agree with mine.

The effect of choline cannot be demonstrated unless an adequate amount of fat is available to overload the cells; hence the importance of normal gastricemptying. The table given by Tasker and Hartroft is said to summarize the observations "on the 211 intestinal sections which contained appreciable fat". It actually shows the results of not more than 89 sections. Presumably at least 122 sections (58 per cent) contained no appreciable fat at the end of three hours-and 14 more may well have been associated with delayed gastric-emptying. From these figures it would appear that, in at least 64 per cent of the material studied by Tasker and Hartroft, it was not possible to demonstrate the effect of choline due to lack of sufficient fat to overload the intestinal cells.

Since none of the important variables most relevant to the problem were controlled or measured, and since the histological criteria used for assessment were incorrect, the conclusions of Tasker and Hartroft are not valid.

Since the preliminary note on the possible effect of choline on fat absorption, we have developed methods for the simultaneous histological and biochemical study of fat absorption. Using these methods with my colleague, Dr. P. E. Sagrott, we 